\title{
실제도로주행을 포함한 주행모드 따른 EURO-6 경유자동차의 배출특성 연구 An Investigation on the Emission Characteristics of Diesel Vehicle with EURO-6 Standard According to Test Mode Including Real-road Driving
}

\author{
이종철 · 박준홍 · 김주원 · 강건우 · 오승택 · 이상현 · 정택호 ${ }^{\dagger} \cdot$ 이종태 \\ Jong Chul Lee · Jun Hong Pack · Ju Won Kim· Gun Woo Kang · Seung Tak Oh • \\ Sang Hyun Lee $\cdot$ Taek Ho Chung ${ }^{\dagger} \cdot$ Jong Tae Lee \\ 국립환경과학원 교통환경연구소 \\ Transportation Pollution Research Center, National Institute of Environmental Research
}

(Received March 29, 2019; Revised April 24, 2019; Accepted April 25, 2019)

\begin{abstract}
Emission certification test mode of diesel vehicles in Korea was changed to the WLTC (Worldwide harmonized Light duty driving Test Cycle) mode with RDE (Real-road Driving Emission) test from NEDC (New European Driving Cycle) mode in September 2017. In this study, investigation on the emission characteristics of diesel vehicle with EURO-6 standard according to NEDC, WLTC and RDE test were carried out for validation of the effectiveness in point of controlling NOx emission. The 18 passenger diesel vehicles having EURO-6 standard were selected to analyze the emission characteristics according to various test mode. In addition, test vehicles were sorted according to after-treatment system with LNT (Lean NOx Trap) and SCR (Selective Catalytic Reduction) for the confirmation of emission characteristics by NOx reduction technologies. From the results of emission characteristics, exhaust emissions of all test vehicles show lower levels than the emission standard at tests, except for NOx. However, NOx emissions of some vehicles exceeded the exhaust gas emission limits at the WLTC mode. Also, it was found that vehicles equipped with the LNT as the after-treatment device had a large fluctuation of NOx emission amount according to the test mode but vehicles using the SCR after-treatment system had less change than the LNT vehicle.

Key Words : On-road emissions, Nitrogen oxides (NOx), Light-duty diesel vehicles, LNT (Lean NOx Trap), SCR (Selective Catalytic Reduction)

요약 : 2017년 9월부터 경유자동차의 배출가스 차대동력계 인증시험이 NEDC 모드에서 WLTC 모드로 변경되었고, 실도로 시험이 추가되었다. 이 연구는 기존의 NEDC 모드와 변경된 WLTC 모드, 그리고 추가된 실도로시험, 이 각각의 시험방법에 따른 대기오염물질 배출특성의 변화를 확인하고, 새로운 배출가스 인증시험의 실효성을 파악하기 위해 진행되었다. 시험은 기존 2014년 유로6 배출인증기준을 통과하는 18 대의 경유자동차로 진행되었으며, NOx 저감장치 별 배출 특성을 확인하기 위하여 LNT 차량과 SCR 차량, 두 그룹으로 분류하여 결과를 분석하였다. 배출가스 분석 결과 NOx를 제외한 배출가스규제 물질들은 시험 모드가 변경되어도 규제치를 넘지 않는 배출량을 보였지만, NOx는 시험 방법에 따라 일부 차종들이 배출가 스 규제치를 넘는 결과를 보였다. LNT를 저감장치로 장착한 차량들이 시험모드에 따라 NOx 배출량 변화가 큰 경우가 많았 고, $\mathrm{SCR}$ 을 사용한 차량은 $\mathrm{LNT}$ 차량에 비해 변화가 적은 것으로 나타났다.
\end{abstract}

주제어 : 실도로 시험, 질소산화물 흡장 촉매, 선택적 촉매 환원장치

\section{1. 서 론}

경유자동차 배출가스는 우리나라 대기오염에 큰 영향을 미치고 있다. 국립환경과학원에서 발간한 보고서 '대기오 염물질 배출량 2015 '에 따르면 도로이동오염원에서 발생되 는 $\mathrm{NOx}$ (질소산화물), $\mathrm{CO}$ (일산화탄소), $\mathrm{PM}_{2.5}$ (입자상물질) 은 총 대기오염물질 배출량의 $31.9 \%, 31.0 \%, 8.9 \%$ 를 차지 하고 있다. $\mathrm{NOx}$ 와 $\mathrm{CO}$ 는 전체 발생원 중 차량에서 발생되 는 것이 가장 많은 비중을 차지하고 있는 것이다. ${ }^{1)}$

이처럼 자동차 배출가스는 대기오염에 큰 비중을 차지하 고 있기 때문에, 환경부는 이를 관리하기 위하여 제작차 배 출허용 기준을 지속적으로 강화시키고 있다. 우리나라의 경유자동차 배출가스 규제기준은 유럽의 규제기준을 도입 하여 사용하고 있으며, 2006년 2009년 8월까지는 EURO-4,
2009년 9월 2014년 9월까지는 EURO-5, 2014년 9월부터 현재까지는 EURO 6 규제기준을 적용하고 있다. ${ }^{2)}$

자동차 제작사들은 자동차 배출규제물질인 $\mathrm{PM}($ Particulate Matter)을 저감시키기 위해 디젤미립자필터(DPF, Diesel particulate filter)를 사용하고 있고, NOx를 저감시키기 위해 배기가스 재순환 장치(EGR, Exhaust Gas Recirculation)와 흡장촉매장치(LNT, Lean NOx Trap), 선택적 촉매 환원장 치(SCR, Selective Catalytic Reduction)를 사용하고 있다. ${ }^{3,4)}$ $\mathrm{NO}_{2}$ 농도는 뚜렷한 감소 경향을 나타내지 않고 있다. 자 동차 배출가스의 NOx 규제기준이 강화됨에도 불구하고, $\mathrm{NO}_{2}$ 농도가 감소하지 않는 이유는 실내 시험실 배출가스 규제시험이 실제 도로에서 발생되는 NOx 배출값을 제대로 반영하지 못하고 있기 때문이며, 다수의 연구결과에서 확 인할 수 있다. ${ }^{5-8)}$ 
이런 부분을 제도적으로 보완하기 위해 2017년 9월부터 실내시험실 주행모드가 NEDC(New European Driving Cycle) 에서 WLTC(Worldwide harmonized Light duty driving Test Cycle)로 변경되었고, 실제 도로에서의 배출량을 측정하기 위한 실도로시험(RDE, Real Driving Emission)이 인증시험 에 추가되었다.

본 연구는 2014년 유로6 규제를 충족시키는 차량 총 18 대를 선정하여 실내시험실에서 NEDC 모드와 WLTC 모드 를 시험하였고, 실도로에서 PEMS(Portable emissions measurement system)를 이용한 RDE 시험을 진행하였다. 시험 결과 분석을 통해 기존의 NEDC 모드와 새로운 WLTC 모 드, 그리고 실도로시험에서 배출되는 규제 오염물질의 배 출특성을 확인하였고, $\mathrm{LNT}$ 차량과 $\mathrm{SCR}$ 차량으로 구분하 여 저감장치에 따른 배출특성 결과를 비교 분석하였다.

\section{2. 시험차량 및 시험방법}

\section{1. 시험차량}

시험에 사용된 차량은 EURO-6 배기규제를 충족시키는 경유자동차 총 18 대이다. $\mathrm{NOx}$ 저감장치를 기준으로 $\mathrm{LNT}$ 를 사용하는 차량 9 대와 $\mathrm{SCR}$ 을 사용하는 차량 9 대 두 그
룹으로 나누었으며, 시험에 따른 그룹별 배출가스 특성을 분석하였다. Table 1은 시험차량들에 대한 스펙이며, Table 2 는 경유차 EURO-6 규제 기준을 나타낸다.

\section{2. 시험장비}

실내시험실에서 진행되는 차량 시험은 차대동력계 위에 서 차량을 주행하며 발생하는 배출가스를 측정하는 방식이 다. Fig. 1은 실내시험실에서 진행되는 시험의 개략도이다. 차대동력계는 실제 도로를 주행할 때 발생하는 도로 주행 저항 값들을 재연하는 장비로서 $\mathrm{AVL}$ 사의 동력계를 사용 하였고, 배출가스 분석기는 HORIBA사의 MEXA- 9200D, 7200 분석기를 사용하였다. $\mathrm{CO}, \mathrm{CO}_{2}$ 는 비분산적외선분석법 (Nondispersive Infrared, NDIR), THC는 열식수소염이온화 검출법(Heated Flame Ionization Detector, HFID), NOx는 화학 발광법(Chemiluminescence Detector, $\mathrm{CLD})$ 을 이용해 측정 하였고, 분석방법은 실시간으로 배출량을 측정하는 MODAL 분석방법과, 각 phase에 따른 총 배출가스 농도를 측정하여 최종적으로 배출량을 계산하는 bag 분석방법을 사용하였으 며, 주행거리 당 배출가스양 $(\mathrm{g} / \mathrm{km})$ 으로 계산하였다.

Fig. 2는 실도로시험과 시험에 쓰이는 PEMS 장비 장착 사진이다. PEMS는 센서스 사의 SEMTECH 장비를 사용하 였다. $\mathrm{CO}, \mathrm{CO}_{2}$ 는 비분산적외선분석법(Nondispersive Infrared,

Table 1. Selected specification of test vehicles

\begin{tabular}{|c|c|c|c|c|c|}
\hline Type & Disp. [cc] & Test Weight [kg] & After Treatment & Fuel & Emission Standard \\
\hline SEDAN & 1582 & 1470 & LNT & DIESEL & EURO6 \\
\hline SEDAN & 1969 & 1700 & LNT & DIESEL & EURO6 \\
\hline SEDAN & 1995 & 1810 & LNT & DIESEL & EURO6 \\
\hline SEDAN & 1997 & 1753 & LNT & DIESEL & EURO6 \\
\hline SEDAN & 2199 & 1930 & LNT & DIESEL & EURO6 \\
\hline SUV & 1956 & 1700 & LNT & DIESEL & EURO6 \\
\hline SUV & 1995 & 1700 & LNT & DIESEL & EURO6 \\
\hline SUV & 1995 & 1810 & LNT & DIESEL & EURO6 \\
\hline SEDAN & 2993 & 1930 & SCR & DIESEL & EURO6 \\
\hline SEDAN & 1560 & 1360 & SCR & DIESEL & EURO6 \\
\hline SEDAN & 1968 & 1810 & SCR & DIESEL & EURO6 \\
\hline SEDAN & 2143 & 1700 & SCR & DIESEL & EURO6 \\
\hline SEDAN & 2967 & 2150 & SCR & DIESEL & EURO6 \\
\hline SEDAN & 2987 & 2270 & SCR & DIESEL & EURO6 \\
\hline \multirow[t]{2}{*}{ SUV } & 1956 & 1700 & SCR & DIESEL & EURO6 \\
\hline & 1968 & 1810 & SCR & DIESEL & EURO6 \\
\hline SUV & 2967 & 2270 & SCR & DIESEL & EURO6 \\
\hline SUV & 2967 & 2270 & SCR & DIESEL & EURO6 \\
\hline
\end{tabular}

Table 2. EURO-6 emission standard

\begin{tabular}{c|ccccc}
\hline & CO & HC + NOx & NOx & PM & PN \\
\hline \hline EURO-6 & $0.5 \mathrm{~g} / \mathrm{km}$ & $0.17 \mathrm{~g} / \mathrm{km}$ & $0.08 \mathrm{~g} / \mathrm{km}$ & $0.0045 \mathrm{~g} / \mathrm{km}$ & $6 * 1011 \# / \mathrm{km}$ \\
\hline
\end{tabular}




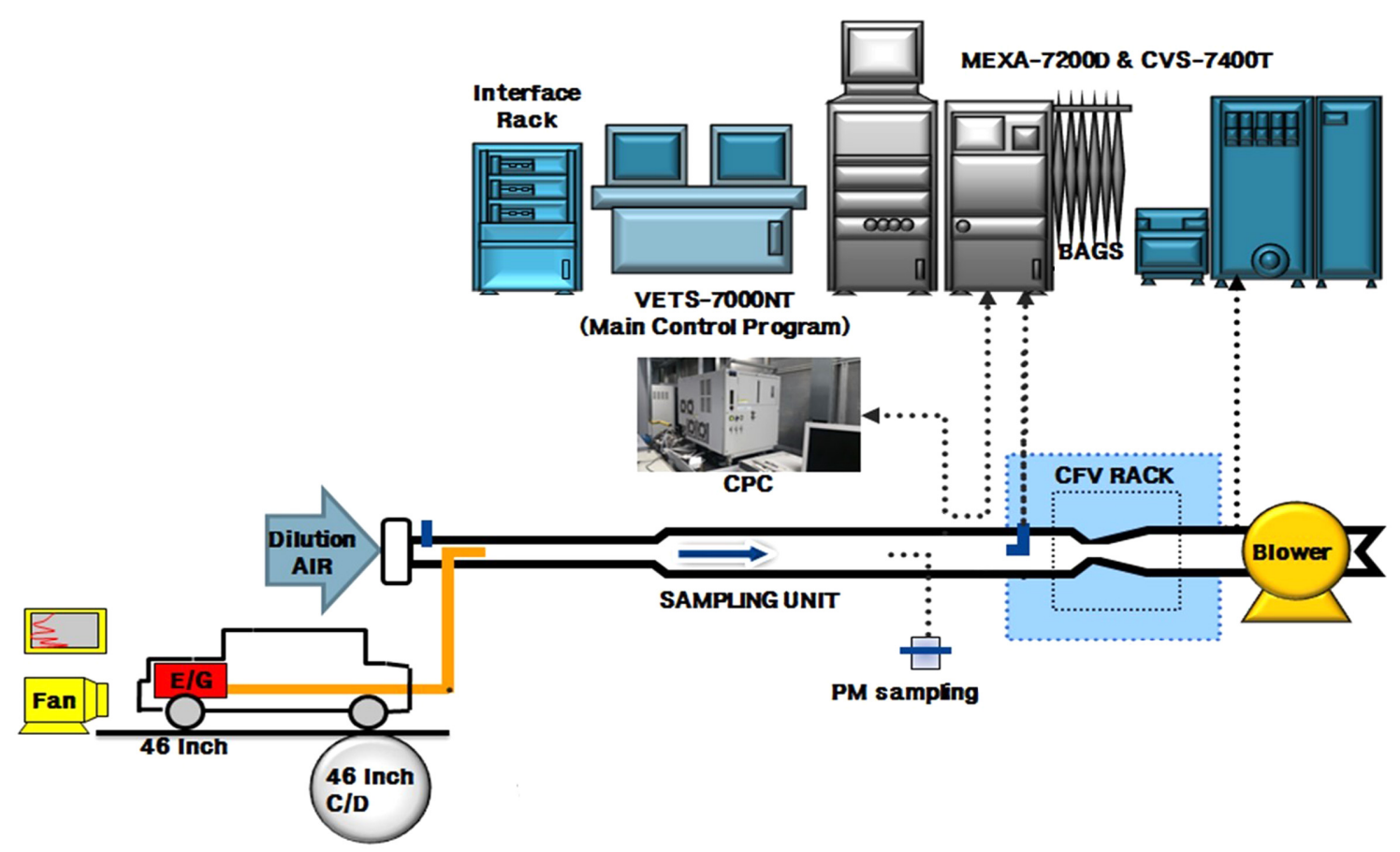

Fig. 1. Schematic view of a chassis dynamometer system.

$\mathrm{NDIR}), \mathrm{NO}, \mathrm{NO}_{2}$ 는 비분산자외선(Non-dispersive UV)방법 을 이용해 측정하였으며, 분석방법은 실시간 배출량을 측 정하는 방법과 $\mathrm{EC}-\mathrm{JRC}$ 에서 $\mathrm{RDE}-\mathrm{LDV}$ 데이터 분석방법으 로 제시한 이동평균구간(MAW, Moving Averaging Window) 을 이용하였다. 이동평균구간 분석 방법은 WLTC 인증모 드에서 발생했던 총 $\mathrm{CO}_{2}$ 배출량의 절반 값을 기준으로, 실제 도로에서 발생하는 $\mathrm{CO}_{2}$ 누적 발생량이 그 값에 도달하였 을 때 하나의 평균 구간을 생성하며, 평균 구간은 1 초 간격 으로 연속적으로 생성된다. 각 이동 평균 구간에서 $\mathrm{NOx}$ 및 $\mathrm{CO}_{2}$ 등 물질의 주행거리 당 배출가스양 $(\mathrm{g} / \mathrm{km})$ 으로 계산하였다. ${ }^{9)}$

이동평균구간 분석방법은 인증시험 시에 실도로 배출가 스 시험 결과의 최종 값을 산정하는 방식에 적용되고 있으 며, 실도로 시험 결과의 산포를 줄여주어 결과를 표준화할 수 있는 계산 방법이라 이동평균구간 분석방법 이용하여

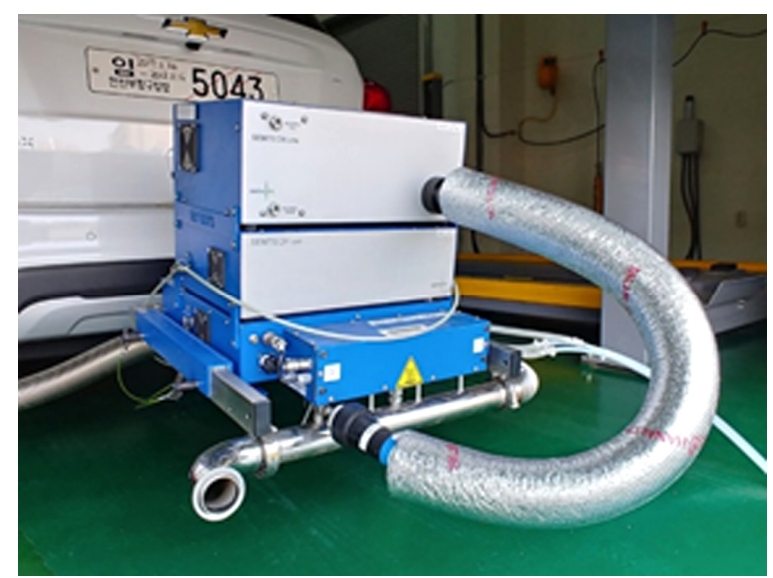

Fig. 2. Photographs of PEMS installation to test vehicle.
분석하였다.

모든 시험 진행 과정과 분석방법은 인증시험에 사용되는 방법에 따라 진행되었으며, 차대동력계시험 데이터와 PEMS 시험 데이터의 신뢰성 확보를 위해 상관성 시험을 진행하 였다. 상관성 시험은 $\mathrm{PEMS}$ 를 차량에 장착 후 차대동력계 에서 WLTC 모드를 주행하는 방식으로 진행하였다. 시험 중 발생되는 배출가스를 차대동력계 분석기와 PEMS로 각 각 측정한 후, 두 장비의 측정값이 차량시험 고시기준의 오 차범위 내에 들어오는지 확인하였다.

\section{3. 시험방법}

실내시험실 시험 진행 과정은 차량을 실제 도로 상황과 유사한 부하 조건을 구현하기 위해 시험모드 진행 전 차대 동력계 롤러 위에 차량을 올려놓고 $80 \mathrm{~km} / \mathrm{h}$ 의 속력으로 30

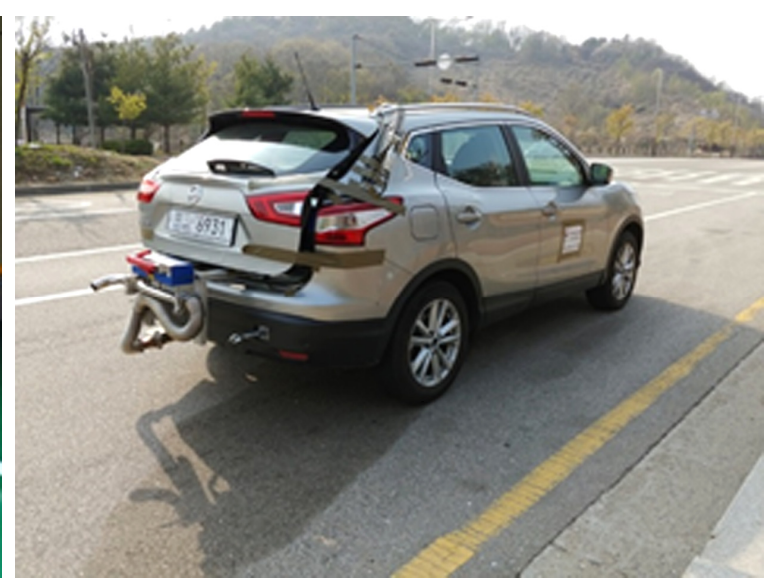

Fig. 2. Photographs of PEMS installation to test vehicle. 

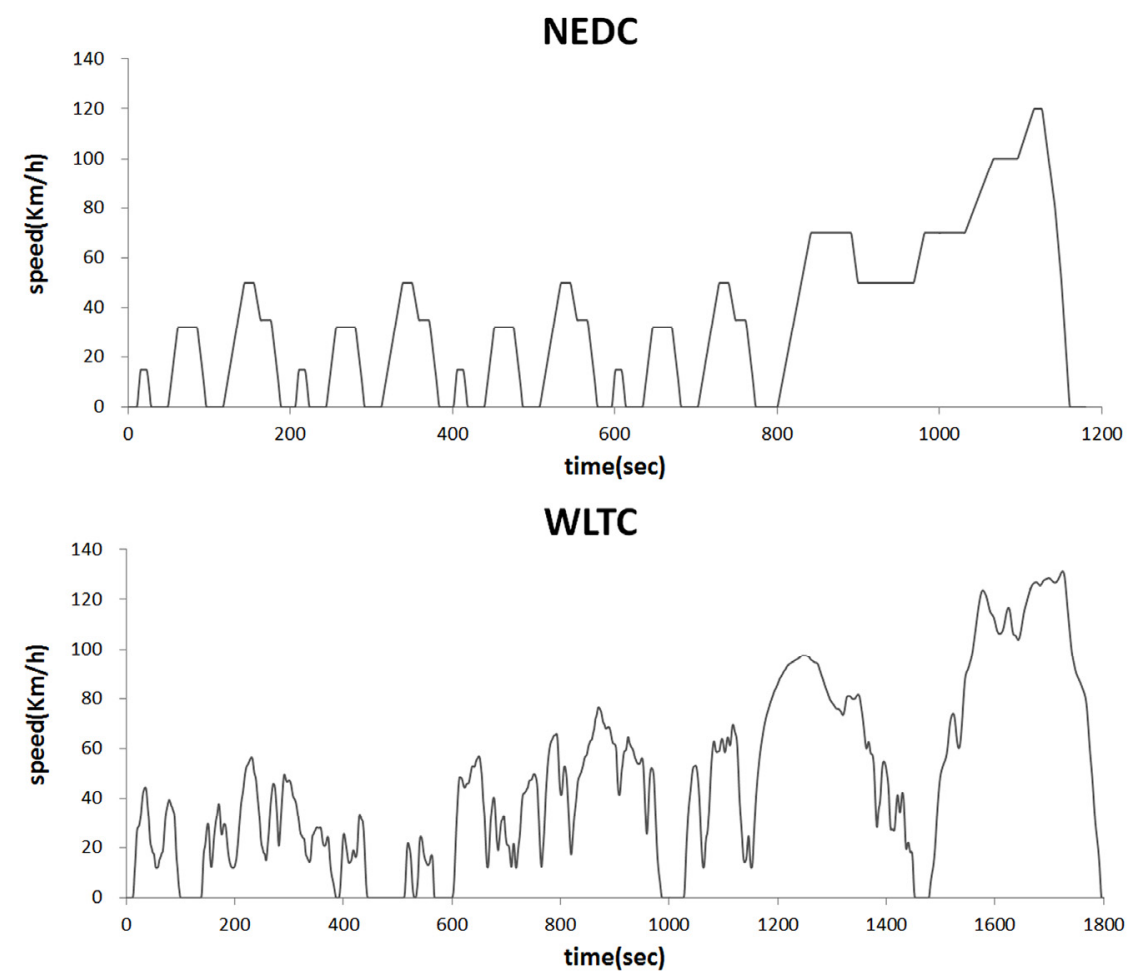

Fig. 3. Driving cycle for laboratory test.

분 주행 후 Coast-down을 실시하였으며, 차량은 시험설정 온도가 유지되는 환경에서 6시간 이상 정차(Soaking)시킨 후 시험을 실시하여 배출가스를 측정하였다.

Fig. 3은 NEDC 모드와 WLTC 모드의 시간에 따른 자동 차 차속 그래프이다. 실내 시험실에서 운전자가 그래프와 같은 속도에 따라 주행하며 시험이 진행된다. NEDC 모드 는 런던, 파리 등 유럽 주요 도시의 표준 주행패턴을 이용 하여 만들어진 모드이며, WLTC 모드는 UN WP.29에서 주 요 5 개국의 평균적인 주행패턴을 이용하여 만들어진 모드 이다. Table 3은 NEDC, WLTC모드의 상세 정보들을 나타 낸다.

실도로시험은 차량에 PEMS를 장착하고 실제 도로를 주 행하는 동안 자동차에서 발생하는 자동차 배출가스를 측정 하는 방법으로 진행하였다. 실도로 시험에 사용된 주행 경 로로는 Fig. 4의 NIER Route3 경로를 사용하였는데, NIER Route3 경로에 대한 자세한 주행정보는 Table 4 를 통해 확 인할 수 있다. 시험 진행 과정은 도심 $(0 \sim 60 \mathrm{~km} / \mathrm{h}) 34 \%$, 교 외(60 90 km/h) 33\%, 고속도로 $(90 \mathrm{~km} / \mathrm{h}) 33 \%$ 를 기준으로 실험을 진행하며, 도로 유형의 주행거리는 $16 \mathrm{~km}$ 이상, 최고

Table 3. Mode driving condition

\begin{tabular}{c|cc}
\hline & NEDC & WLTC \\
\hline \hline Distance $(\mathrm{km})$ & 11.007 & 23.26 \\
Ave. speed $(\mathrm{km} / \mathrm{h})$ & 40.65 & 46.3 \\
Max. speed $(\mathrm{km} / \mathrm{h})$ & 120 & 131.6 \\
Mode time $(\mathrm{sec})$ & 1180 & 1800 \\
\hline
\end{tabular}

Table 4. Information of KOR-NIER Route 3

\begin{tabular}{c|cc}
\hline & NEDC & WLTC \\
\hline \hline Distance $(\mathrm{km})$ & 11.007 & 23.26 \\
Ave. speed $(\mathrm{km} / \mathrm{h})$ & 40.65 & 46.3 \\
Max. speed $(\mathrm{km} / \mathrm{h})$ & 120 & 131.6 \\
Mode time $(\mathrm{sec})$ & 1180 & 1800 \\
\hline
\end{tabular}

속도는 $145 \mathrm{~km} / \mathrm{h}$, 도심 평균차속: $15 \sim 40 \mathrm{~km} / \mathrm{h}$, 주행시간: $90 \sim 120$ 분 동안 시험이 진행하였다. ${ }^{10)}$

\section{3. 결과 및 분석}

$\mathrm{NEDC}, \mathrm{WLTC}$ 모드와 RDE 시험을 진행하며 획득한 실시 간 데이터와 거리당 배출량을 바탕으로 결과를 분석하였다.

\section{1. 시험방법 별 주행조건 반영 특성}

Fig. 5는 시험이 진행되는 동안 $\mathrm{OBD}$ 를 통해 취득한 차량 의 실시간 데이터를 이용해 만든 그래프로 엔진 회전 속도 에 따른 엔진 부하의 정도를 나타낸다. 이 그래프를 통해 시험에서 주로 사용하는 엔진 회전 속도와 부하의 정도를 파악할 수 있으며, 이를 통해 각각의 시험방법이 얼마나 다 양한 운행조건을 반영하고 있는지를 알 수 있다. NEDC 모 드의 경우 시험이 진행되는 동안 엔진 회전 속도 1000 2000 $\mathrm{RPM}$, 엔진 부하 $30 \sim 90 \%$ 영역을 주로 사용하는 것을 알 수 있고, WLTC 모드는 RPM 750 2500 영역, 로드 $0 \sim 100 \%$ 


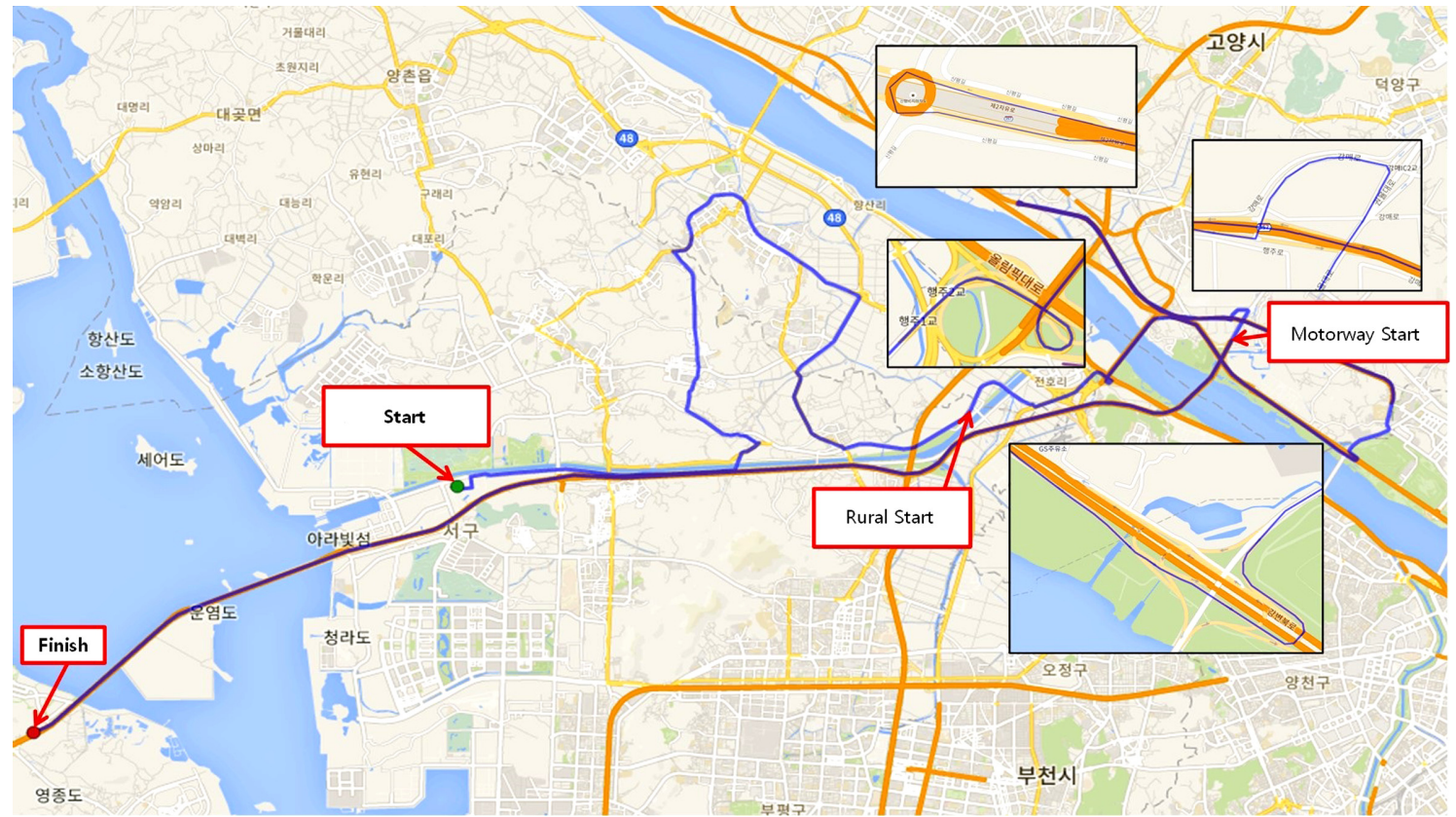

Fig. 4. Map of KOR-NIER Route 3.

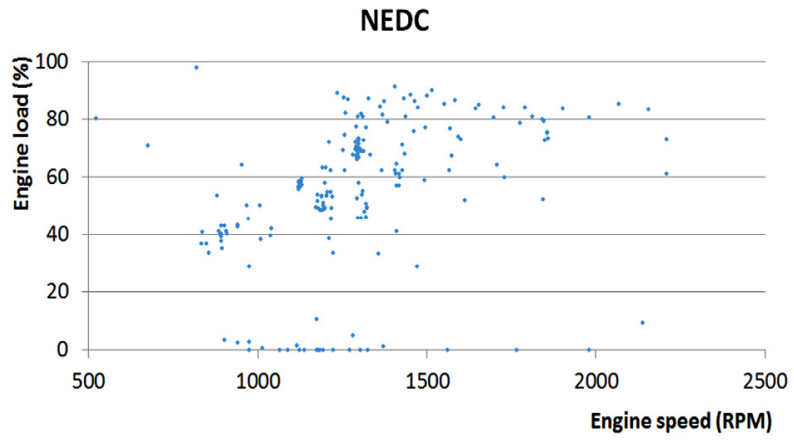

WLTC

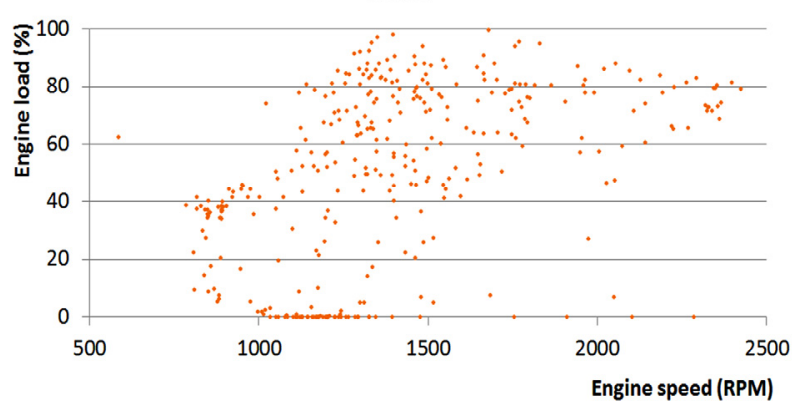

RDE

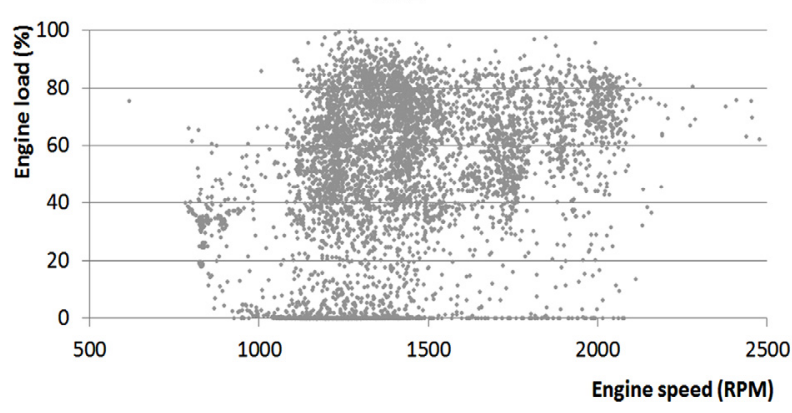

Fig. 5. Engine speed-load distribution in each test mode.
을 이용하는 것을 알 수 있다. NEDC 모드 대비 WLTC에 서 더 넓은 영역을 사용하고 있으며, 이를 통해 NEDC 재 현되지 않는 엔진 운전 영역이 WLTC 조건에서 이루어지 는 것을 알 수 있다. 실도로 시험은 전체적으로는 WLTC와 비슷한 750 2500 RPM 영역, 로드 0 100\% 영역을 사용하 고 있지만, WLTC와 비교하면 더욱더 많은 양의 데이터가 다양하게 분포하고 있는 것을 확인할 수 있다. 이를 통해 $\mathrm{WLTC}$ 모드가 NEDC와 비교해 실도로시험 조건을 잘 재 현했지만, 실제 도로 조건과 비교하면 전체적인 데이터의 양에서 부족하다는 것을 알 수 있다.

\subsection{NEDC-WLTC 모드에서의 가스상물질 배출결과 비교}

Fig. 6은 NEDC와 WLTC 모드에서의 가스상 물질 배출을 비교하기 위한 그래프로 $\mathrm{LNT}$ 와 SCR이 장착된 차량을 구 분하여 보여주고 있다.

$\mathrm{CO}$ 배출량은 $\mathrm{LNT}$ 장착 차량은 $\mathrm{NEDC}$ 모드에서 평균 $0.032 \mathrm{~g} / \mathrm{km}$, WLTC 모드에서 평균 $0.023 \mathrm{~g} / \mathrm{km}$ 이었고, SCR 장착 차량은 NEDC $0.099 \mathrm{~g} / \mathrm{km}$, WLTC $0.078 \mathrm{~g} / \mathrm{km}$ 이었다. $\mathrm{NEDC}$ 대비 WLTC에서 LNT 차량은 $27.6 \%, \mathrm{SCR}$ 차량은 $21.6 \%$ 배출량이 감소되는 경향을 보였다.

$\mathrm{NOx}$ 배출량은 LNT 차량은 NEDC 모드에서 평균 0.027 $\mathrm{g} / \mathrm{km}, \mathrm{WLTC}$ 모드에서 평균 $0.116 \mathrm{~g} / \mathrm{km}$ 이었고, SCR 차량 은 NEDC $0.048 \mathrm{~g} / \mathrm{km}$, WLTC $0.077 \mathrm{~g} / \mathrm{km}$ 이었다. NEDC 대 비 $\mathrm{WLTC}$ 에서 $\mathrm{LNT}$ 차량은 $332.7 \%, \mathrm{SCR}$ 차량은 $60.5 \%$ 증 가되는 경향을 보였다.

$\mathrm{CO}_{2}$ 배출량은 LNT 차량은 NEDC 모드에서 평균 $159 \mathrm{~g} / \mathrm{km}$, WLTC 모드에서 평균 $160 \mathrm{~g} / \mathrm{km}$ 이었고, SCR 차량은 NEDC $171 \mathrm{~g} / \mathrm{km}$, WLTC $170 \mathrm{~g} / \mathrm{km}$ 이었다. NEDC 대비 WLTC에서 $\mathrm{LNT}$ 차량은 $0.2 \%$ 가 증가, $\mathrm{SCR}$ 차량은 $0.1 \%$ 감소되는 경 

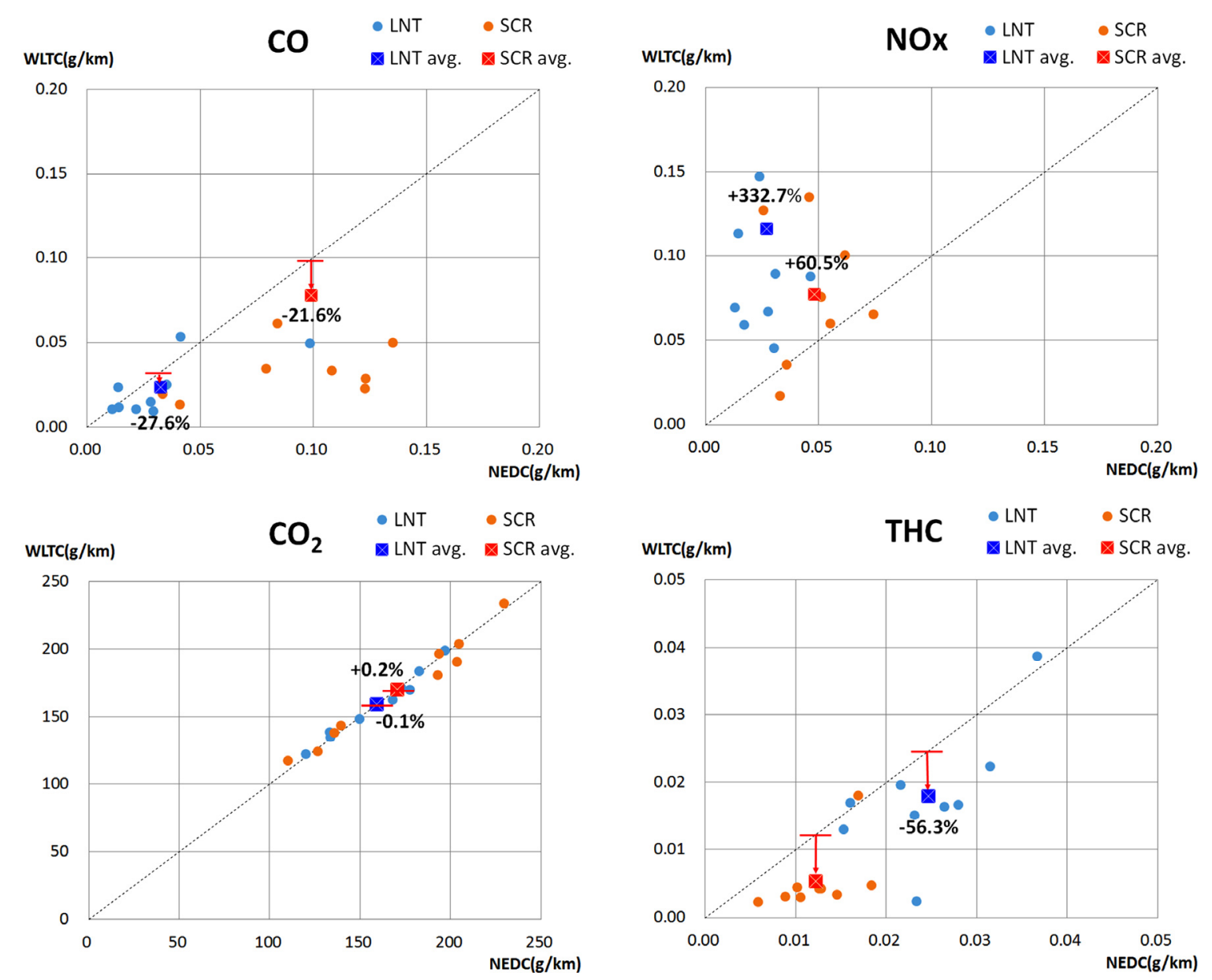

Fig. 6. Comparison of Gas Air Pollutant emission characteristics between NEDC Cycle and WLTC Cycle.

향을 보였다.

$\mathrm{THC}$ 의 배출량은 $\mathrm{LNT}$ 차량은 $\mathrm{NEDC}$ 모드에서 평균 $0.025 \mathrm{~g} / \mathrm{km}, \mathrm{WLTC}$ 모드에서 평균 $0.018 \mathrm{~g} / \mathrm{km}$ 이었고, SCR 차량은 NEDC $0.012 \mathrm{~g} / \mathrm{km}$, WLTC $0.005 \mathrm{~g} / \mathrm{km}$ 이었다. NEDC 대비 $\mathrm{WLTC}$ 에서 $\mathrm{LNT}$ 차량은 $26.9 \%$, SCR차량은 $56.3 \%$ 감 소되는 경향을 보였다.

시험모드에 따른 배출량 변화 추이를 보면 NEDC 대비 $\mathrm{WLTC}$ 에서 $\mathrm{NOx}$ 는 증가하고, $\mathrm{CO}$ 와 $\mathrm{THC}$ 는 감소하였으며 $\mathrm{CO}_{2}$ 는 모드에 따른 변화량이 거의 없었다. $\mathrm{NOx}$ 의 경우에는 대부분의 차량이 WLTC 모드에서 배출량이 증가하였는데, LNT를 장착한 차량이 특히 많이 증가함을 확인할 수 있었다.

규제 기준으로 변화량을 판단하면 CO의 EURO-6 배출규 제기준은 $0.5 \mathrm{~g} / \mathrm{km}$ 인데, 한대의 차량 이 WLTC 모드에서 $0.43 \mathrm{~g} / \mathrm{km}$ 배출되었을 뿐, 대부분은 $0.2 \mathrm{~g} / \mathrm{km}$ 이하로 배출 되었기 때문에 두 시험 모두 규제기준을 충족시키는데 문 제가 없었고, $\mathrm{NOx}$ 의 배출허용기준은 $0.08 \mathrm{~g} / \mathrm{km}$ 으로 NEDC 에서는 모든 차량이 배출허용기준을 충족했지만, LNT 장 착 차량 5 대, $\mathrm{SCR}$ 장착 차량 3 대가 WLTC에서 배출허용기 준을 충족시키지 못하였다. $\mathrm{THC}$ 는 $\mathrm{NOx}$ 와 합산한 값으로 규제하고 있는데 NOx의 규제 기준치는 $0.08 \mathrm{~g} / \mathrm{km}$ 이고, $\mathrm{HC}+\mathrm{NOx}$ 합산 규제치는 $0.17 \mathrm{~g} / \mathrm{km}$ 이기 때문에 $\mathrm{THC}$ 는
규제기준에서 $0.07 \mathrm{~g} / \mathrm{km}$ 정도의 여유를 가지고 있다고 볼 수 있다. 대부분의 차량 배출량이 $0.04 \mathrm{~g} / \mathrm{km}$ 이하로 배출되 었기 때문에 NEDC와 WLTC 모드 전부 배출가스 규제기준 을 충족시키는 데는 큰 문제가 없는 것을 확인할 수 있다.

\subsection{NEDC-WLTC 모드에서의 입자상 물질 결과 비교}

Fig. 7은 입자상 물질인 PM과 PN의 배출 결과로 LNT와 $\mathrm{SCR}$ 이 장착된 차량을 구분하여 보여주고 있다. $\mathrm{PM}$ 의 경 우 LNT 차량은 NEDC 모드에서 평균 $0.358 \mathrm{mg} / \mathrm{km}$, WLTC 모드에서 평균 $0.429 \mathrm{mg} / \mathrm{km}$ 을 배출하였고, $\mathrm{SCR}$ 차량은 NEDC $0.318 \mathrm{mg} / \mathrm{km}$, WLTC $0.911 \mathrm{mg} / \mathrm{km}$ 를 나타내고 있 다. NEDC 대비 WLTC에서 LNT 차량은 $19.6 \%, \mathrm{SCR}$ 차량 은 $186.6 \%$ 증가했고, $\mathrm{SCR}$ 차량 중 한대가 $\mathrm{PM}$ 배출량이 높았기 때문에 높게 배출된 차량을 제외하면 증가량은 $72.4 \%$ 가 됨을 알 수 있다.

$\mathrm{PN}$ 의 경우 $\mathrm{LNT}$ 장착 차량은 $\mathrm{NEDC}$ 모드에서 평균 $1.049 * 10^{11} \# / \mathrm{km}$, WLTC 모드에서 평균 $6.937 * 10^{10} \# / \mathrm{km}$ 을 배출하였고, SCR 장착 차량은 $\mathrm{NEDC} 5.861 * 10^{10} \# / \mathrm{km}$, WLTC $4.735^{*} 10^{10} \# / \mathrm{km}$ 를 배출하였다. NEDC 대비 WLTC 에서 $\mathrm{LNT}$ 차량은 $33.8 \%$ 감소, $\mathrm{SCR}$ 차량은 $19.2 \%$ 감소하 는 경향을 보였다. 

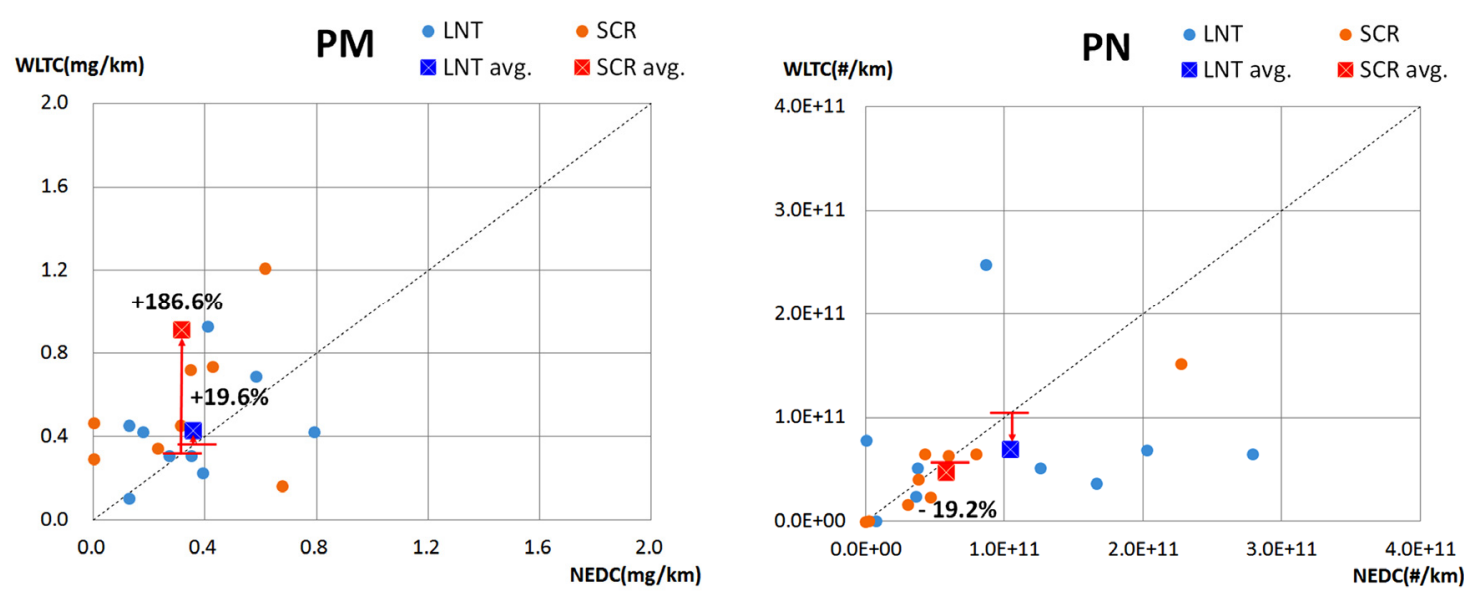

Fig. 7. Comparison of Particulate Matter emission characteristics between NEDC Cycle and WLTC Cycle.
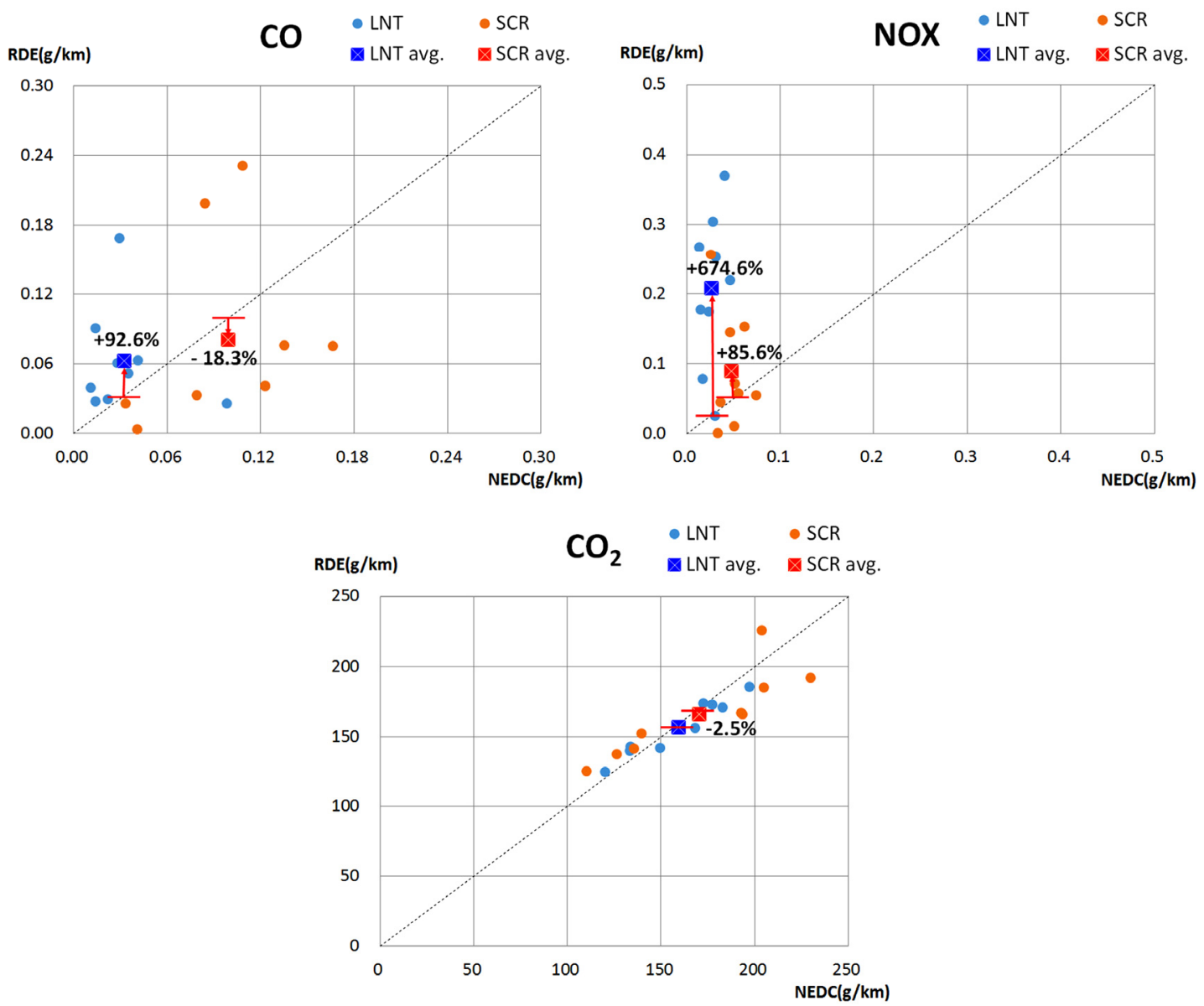

Fig. 8. Comparison of Gas Air Pollutant emission characteristics between NEDC Cycle and RDE test.

시험모드에 따른 배출량 변화 추이를 보면 NEDC 대비 $\mathrm{WLTC}$ 에서 $\mathrm{PM}$ 는 증가하고, $\mathrm{PN}$ 은 감소하는 경향을 보였다. EURO-6에서 PM은 $4.5 \mathrm{mg} / \mathrm{km}, \mathrm{PN}$ 은 $6.0^{*} 10^{11}$ 의 규제기 준을 가지고 있는데, $\mathrm{PM}$ 과 $\mathrm{PN}$ 대부분이 모든 시험에서 규 제기준보다 많이 낮은 배출량을 보임을 알 수 있다.

\subsection{NEDC-RDE 배출가스 결과 비교}

Fig. 8은 NEDC와 RED 시험에서의 가스상 물질 배출을
비교하기 위한 그래프로 LNT와 SCR이 장착된 차량을 구 분하여 보여주고 있다. $\mathrm{PEMS}$ 장비는 $\mathrm{CO}, \mathrm{NOx}, \mathrm{CO}_{2}$ 만 측 정 가능하고, $\mathrm{RDE}$ 시험은 $\mathrm{CO}$ 와 $\mathrm{NOx}$ 만 규제물질로 구분 하고 있기 때문에, 실내 시험실 주행모드와 실도로시험 간 의 비교는 $\mathrm{CO}, \mathrm{NOx}, \mathrm{CO}_{2}$ 로 진행하였다.

$\mathrm{CO}$ 배출량은 LNT 차량은 NEDC 모드에서 평균 $0.032 \mathrm{~g} / \mathrm{km}$, $\mathrm{RDE}$ 시험에서 $0.062 \mathrm{~g} / \mathrm{km}$ 이었고, $\mathrm{SCR}$ 차량은 $\mathrm{NEDC}$ 모드 에서 평균 $0.099 \mathrm{~g} / \mathrm{km}, \mathrm{RDE}$ 시험에서 $0.081 \mathrm{~g} / \mathrm{km}$ 이었다. 
$\mathrm{NEDC}$ 모드 대비 $\mathrm{RDE}$ 시험에서 $\mathrm{LNT}$ 차량은 $92.6 \%$ 증가, $\mathrm{SCR}$ 차량은 $18.3 \%$ 감소되는 경향을 보였다.

$\mathrm{NOx}$ 배출량은 LNT 차량은 NEDC 모드에서 평균 0.027 $\mathrm{g} / \mathrm{km}, \mathrm{RDE}$ 시험에서 $0.208 \mathrm{~g} / \mathrm{km}$ 이었고, $\mathrm{SCR}$ 차량은 $\mathrm{NEDC}$ 모드에서 평균 $0.048 \mathrm{~g} / \mathrm{km}, \mathrm{RDE}$ 시험에서 $0.089 \mathrm{~g} / \mathrm{km}$ 이었 다. $\mathrm{NEDC}$ 모드 대비 $\mathrm{RDE}$ 시험에서 $\mathrm{LNT}$ 차량은 $674.6 \%$, $\mathrm{SCR}$ 차량은 $85.6 \%$ 증가되는 경향을 보였다.

$\mathrm{CO}_{2}$ 배출량은 $\mathrm{LNT}$ 차량은 NEDC 모드에서 평균 $159 \mathrm{~g} / \mathrm{km}$, $\mathrm{RDE}$ 시험에서 $157 \mathrm{~g} / \mathrm{km}$ 이었고, SCR 차량은 NEDC 모드 에서 평균 $170 \mathrm{~g} / \mathrm{km}, \mathrm{RDE}$ 시험에서 $166 \mathrm{~g} / \mathrm{km}$ 이었다. $\mathrm{NEDC}$ 모드 대비 $\mathrm{RDE}$ 시험에서 $\mathrm{LNT}$ 차량은 $1.5 \%$ 감소, $\mathrm{SCR}$ 차량은 $2.5 \%$ 감소되는 경향을 보였다.

시험모드에 따른 배출량 변화 추이를 보면 $\mathrm{CO}$ 는 LNT 차량만 증가하는 경향을 보였고, $\mathrm{CO}_{2}$ 는 변화가 거의 없었 으며 $\mathrm{NOx}$ 는 상당수의 차량이 $\mathrm{NEDC}$ 대비 $\mathrm{RDE}$ 에서 증가 하는 경향을 보였다. $\mathrm{NOx}$ 의 경우에는 대부분의 차량이 $\mathrm{RDE}$ 모드에서 배출량이 증가하였는데, 이번 비교에서도 LNT 차량이 특히 많이 증가함을 확인할 수 있었다.

\subsection{WLTC-RDE 배출가스 결과 비교}

Fig. 9는 WLTC와 RED 시험에서의 가스상 물질 배출을 비교하기 위한 그래프로 $\mathrm{LNT}$ 와 SCR이 장착된 차량을 구분
하여 보여주고 있다. $\mathrm{CO}$ 배출량은 LNT 차량은 WLTC 모드 에서 평균 $0.023 \mathrm{~g} / \mathrm{km}, \mathrm{RDE}$ 시험에서 $0.062 \mathrm{~g} / \mathrm{km}$ 이었고, $\mathrm{SCR}$ 차량은 WLTC 모드에서 평균 $0.078 \mathrm{~g} / \mathrm{km}, \mathrm{RDE}$ 시험에 서 $0.081 \mathrm{~g} / \mathrm{km}$ 이었다. WLTC 모드 대비 RDE 시험에서 LNT 차 량은 $165.9 \%$ 증가, $\mathrm{SCR}$ 차량은 $4.3 \%$ 증가되는 경향을 보였다. $\mathrm{NOx}$ 의 경우 LNT 차량은 WLTC 모드에서 평균 0.116 $\mathrm{g} / \mathrm{km}, \mathrm{RDE}$ 시험에서 $0.209 \mathrm{~g} / \mathrm{km}$ 을 배출하였고, SCR 차량 은 WLTC 모드에서 평균 $0.077 \mathrm{~g} / \mathrm{km}, \mathrm{RDE}$ 시험에서 0.089 $\mathrm{g} / \mathrm{km}$ 를 배출하였다. WLTC 모드 대비 RDE 시험에서 LNT 차량은 $79.0 \%, \mathrm{SCR}$ 차량은 $15.6 \%$ 증가되는 경향을 보였다.

$\mathrm{CO}_{2}$ 의 경우 LNT 차량은 WLTC 모드에서 평균 $160 \mathrm{~g} / \mathrm{km}$, $\mathrm{RDE}$ 시험에서 $157 \mathrm{~g} / \mathrm{km}$ 을 배출하였고, SCR 차량은 WLTC 모드에서 평균 $170 \mathrm{~g} / \mathrm{km}, \mathrm{RDE}$ 시험에서 $166 \mathrm{~g} / \mathrm{km}$ 를 배출 하였다. WTLC 모드 대비 RDE 시험에서 LNT 차량은 $1.7 \%$ 감소, $\mathrm{SCR}$ 차량은 $2.4 \%$ 감소되는 경향을 보였다.

시험모드에 따른 배출량 변화 추이를 보면 $\mathrm{CO}$ 는 LNT 차량만 $\mathrm{WLTC}$ 대비 $\mathrm{RDE}$ 에서 증가하는 경향을 보였고, $\mathrm{CO}_{2}$ 는 변화가 거의 없었으며, NOx는 WLTC 대비 RDE에 서 증가하는 경향을 보였다. NOx는 이번 비교에서도 LNT 차량이 더 많이 증가함을 확인할 수 있었다. LNT 차량만 $\mathrm{NEDC}$ 와 WLTC 대비 실도로에서 $\mathrm{CO}$ 배출량이 증가하는 이유는 $\mathrm{LNT}$ 특성에 따르는 것으로 판단되는데, LNT는 촉
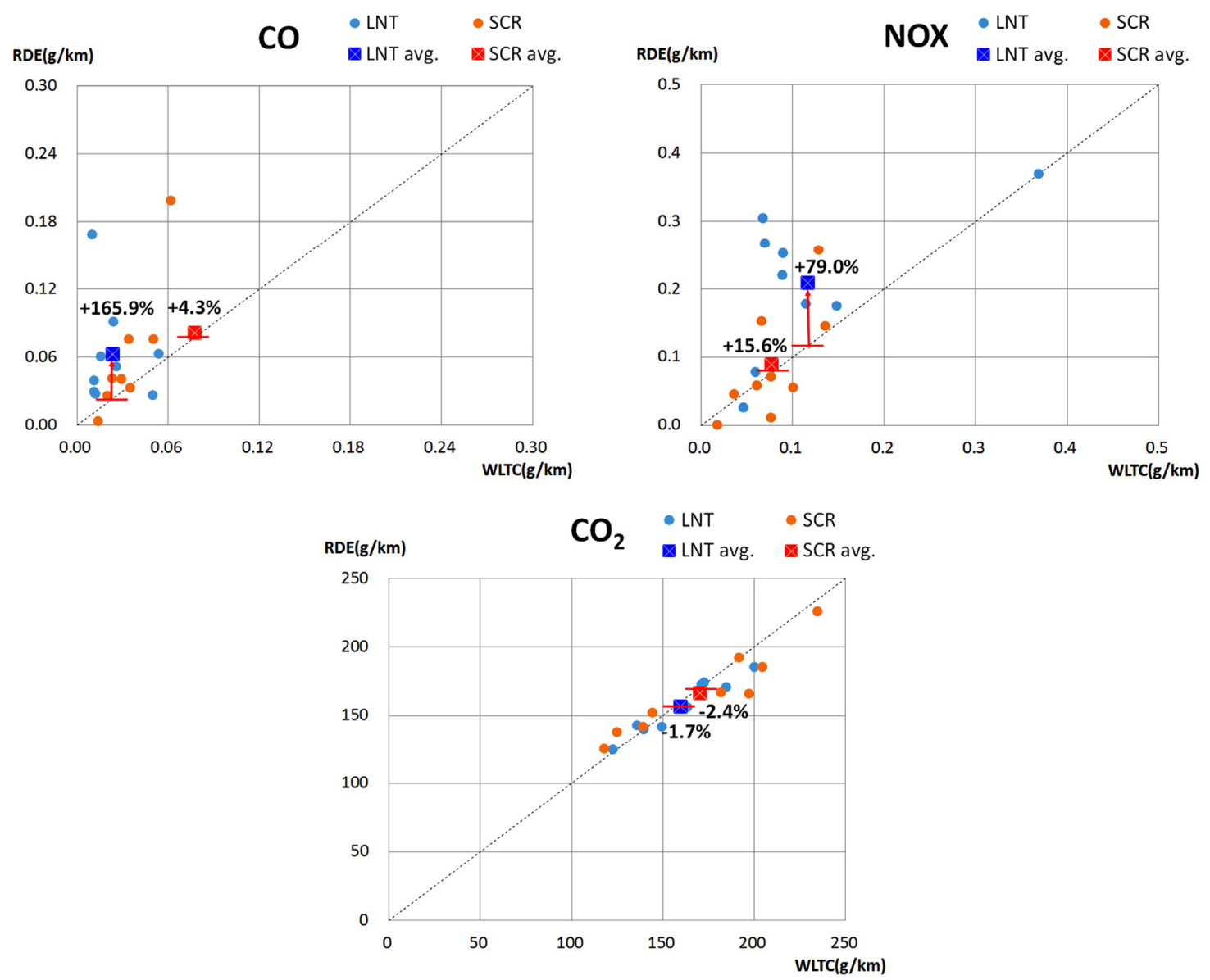

Fig. 9. Comparison of Gas Air Pollutant emission characteristics between WLTC Cycle and RDE test. 
매 내에 흡장된 $\mathrm{NOx}$ 를 일시적으로 농후한 공연비를 이용 하여 $\mathrm{N}_{2}$ 로 정화시키는 방법을 이용한다. 그 과정에서 많은 연료 분사로 인해 배출가스 온도가 증가하고, 환원제로 사 용되는 $\mathrm{THC}$ 와 $\mathrm{CO}$ 의 농도가 증가하게 되는데, $\mathrm{NEDC}$ 와 WLTC 모드에서는 환원 과정이 주로 일어나지 않지만 실 도로시험은 시험 시간이 길기 때문에 주기적으로 환원 과 정이 발생하고 그 과정에서 $\mathrm{CO}$ 의 배출량이 늘어난 것으로 보인다. ${ }^{11)}$ 하지만 늘어난 배출량도 배출가스 규정을 맞추 기에 충분하기에 문제가 되지 않을 것으로 보인다.

\section{6. 시험 평균차속에 따른 배출특성}

Fig. 10은 시험 phase 단위의 평균 속도별 NOx 배출량을 보여주는 그래프로 저감장치에 따라 구분하였다. 저속구간 의 경우 $\mathrm{SCR}$ 을 장착한 차량이 $\mathrm{LNT}$ 를 장착한 차량에 비해 배출량이 더 많은 것을 확인할 수 있으며, 중속구간과 고속 구간으로 갈수록 $\mathrm{SCR}$ 차량이 $\mathrm{LNT}$ 차량에 비해 더 낮은 $\mathrm{NOx}$ 배출량을 보이는 것을 확인할 수 있었다.

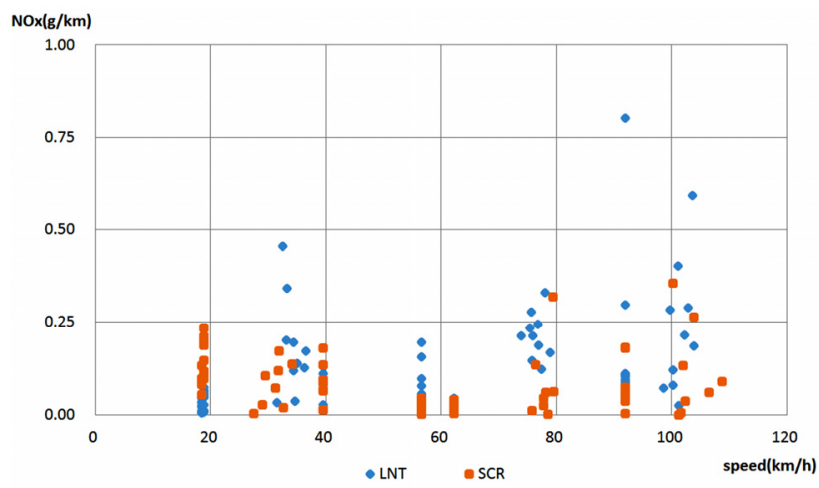

Fig. 10. NOx emissions of average vehicle speed.

\section{7. 저감장치 별 $\mathrm{CO}_{2}$ 배출량에 따른 $\mathrm{NOx}$ 배출특성}

Fig. 11은 시험과정 중에 발생하는 $\mathrm{CO}_{2}$ 와 $\mathrm{NOx}$ 순간 배출 량을 그래프이다. 차량 한 대가 실험 진행하는 동안 발생한 양을 $1 \mathrm{~Hz}$ 단위로 그래프로 표현한 것이다.

$\mathrm{NOx}$ 제어가 원활히 되고 있는 것을 확인할 수 있지만, WLTC 모드에서는 중간 영역, $\mathrm{RDE}$ 모드에서는 $\mathrm{CO}_{2}$ 배출 이 많은 영역에서 $\mathrm{NOx}$ 제어가 원활히 되지 않는 것을 확



인할 수 있다.

$\mathrm{SCR}$ 장착 차량의 경우 대부분의 상황에서 $\mathrm{NOx}$ 제어가 원활히 되는 것을 확인할 수 있었고, 특히 $\mathrm{RDE}$ 시험에서 $\mathrm{CO}_{2}$ 배출이 많은 영역에서 $\mathrm{LNT}$ 장착 차량과 비교하여 $\mathrm{NOx}$ 제어가 잘 되고 있는 것을 확인할 수 있었다.

시험 결과들을 종합적으로 검토하였을 때 알려진 것처럼 암모니아 $\left(\mathrm{NH}_{3}\right)$ 를 환원제로 사용하는 $\mathrm{SCR}$ 이 LNT보다는 $\mathrm{NOx}$ 를 저감하기에 더 우수한 특징을 갖는다는 것을 확인 할 수 있었다. ${ }^{12}$

\section{4. 결론}

본 연구에서는 시험모드 및 방법에 따른 경유자동차의 배출가스 특성을 측정 및 분석하였으며, 그 결론은 다음과 같다.

1) 기존 배출가스 시험에 사용되던 NEDC모드가 WLTC 모드로 변경되었다. WLTC가 NEDC 보다는 실제 주행했을 때의 엔진 회전 속도와 엔진 부하를 잘 반영하고 있지만, 실제 도로 시험(RDE)에 반영되는 주행조건과 비교하였을 때는 그 반영 수준에 한계가 있다.

2) 시험방식에 따른 배출가스 변화량은 $\mathrm{NOx}$ 의 경우 대 부분의 차량이 NEDC, WLTC, 실도로시험 순으로 배출량 이 증가하는 경향을 보였다. $\mathrm{CO}$ 는 $\mathrm{LNT}$ 차량이 $\mathrm{SCR}$ 차량 에 비해 실도로시험에서는 배출량이 크게 증가하는 경향을 보였지만 배출허용기준은 충분히 만족하는 수준이었다. $\mathrm{CO}_{2}$ 는 시험방식에 따른 영향을 크게 받지 않았다.

3) NEDC 모드에서의 NOx 배출량은 모든 차량이 배출허 용기준에 적합하였지만, WLTC, RDE 시험에서는 배출허용 기준을 초과하는 경우가 다수 발생되었다. NOx 저감장치 종류에 따라서도 차이를 보였는데, LNT를 사용하는 차량 에 비해 $\mathrm{SCR}$ 을 사용하는 차량이 $\mathrm{NOx}$ 배출량 저감에 보다 효과적이었다.

4) 변경된 인증 조건을 만족시키기 위해서는 SCR을 장 착하는 것이 유리해 보이나, $\mathrm{SCR}$ 을 장착하는 차량 중 인증 기준을 충족시키기 위해 보완이 필요한 차량들도 존재하였 다. 또한 WLTC 모드는 RDE 도로 조건을 대신하기에는 부

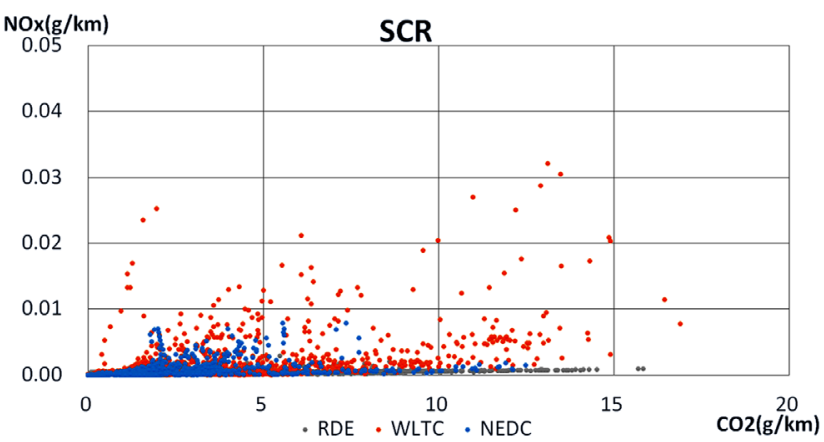

Fig. 11. NOx emission by carbom dioxide emission by each reduction device. 
족하므로, 경유차의 실효적인 $\mathrm{NOx}$ 저감을 위해서는 실도 로 배출가스 시험을 도입하는 것이 타당함을 확인할 수 있 었다.

\section{KSEE}

\section{Acknowledgement}

본 논문은 환경부의 재원으로 국립환경과학원의 지원을 받아 수행하였습니다(NIER-RP2018-120).

\section{References}

1. National Institute of Environmental Research, "National Air Pollutants Emission 2015," National Institute of Environmental Research (2018).

2. UN ECE Regulation No. 83, "Uniform Provisions Concerning the Approval of Vehicles with Regards to the Emission of Pollutants According to Engine Fuel Requirements"

3. You, J. B. and Park, S. S., "Investigation of EGR and LNT control strategies for light-duty diesel engine emissions control," Master thesis, Korea University, Seoul 02841 (2013).

4. Jang, W. W. and Park, S. S., "Evaluation of nitrogen oxides (NOx) emission and its after-treatment system performance characteristics from diesel passenger vehicles on real-world driving with ambient temperature effects," Doctoral thesis, Korea University, seoul 02841 (2013).

5. Joumard, R., Andre, M., Vidon, R., Tassel, P. and Pruvost, C., "Influence of Driving Cycles on Unit Emissions from Passenger Cars," Atmos. Environ., 34(27), 4621 4628 (2000).

6. Pelkmans, L. and Debal, P., "Comparison of On-road Emissions with Emissions Measured on Chassis Dynamometer Test Cycles," Transp. Res. D Transp. Environ.,, 11(4), 233 241(2006).

7. Andre, M., Joumard, R., Vidon, R., Tassel, P. and Perret, P., "Real-world European Driving Cycles, for Measuring Pollutant Emissions from Highand Low-powered Cars," Atmos. Environ., 40(31), 5944 5953(2006).

8. Ministry of Land, Infrastructure and Transport, "Annual Traffic Volume Report 2017," Ministry of Land, Infrastructure and Transport (2018).

9. National Institute of Environmental Research, "A Study of Real Driving Emissions-Light Duty Vehicles (RDELDV) Measured with PEMS," NIER-SP2016-073 (2016).

10. Kang, G. W., Lee, J. T., Park, J. H., Cha, J. P. and Chon, M. S., "Development of Korea RDE Routes for On-rode Emissions Measurement of Light Duty Vehicles," Trans. KSAE., 25(3), 287 296(2017).

11. Parks, J., West, B., Swartz, M. and Huff, S., "Characterization of Lean NOx Trap Catalysts with In-Cylinder Regeneration Strategies," SAE 2008-01-0448 (2008).

12. Johnson, T. V., "Diesel Emission Control in Review," SAE 2006-01-0030 (2006). 